\title{
Determining the Characteristics of Sodium Benzoate (E211) Production Using Mathematical Method
}

\author{
Anita Kovač Kralj*
}

Faculty of Chemistry and Chemical Engineering, University of Maribor, Smetanova 17, Maribor, Slovenia

\begin{abstract}
The productivity of a particular product is highly effective if we know the chemical kinetics. Determining chemical kinetics requires a fundamental knowledge of reactants' declining concentrations or the formation of product concentration. Concentration can be determined by double-linear extrapolation, using the conductivity measurement of strong electrolytes. This method is based on two linear sloped-lines from which the linear constants from different diagrams can be read:

The first diagram represents linear time dependence regarding difference in conductivity

2) The second diagram represents linear difference in conductivity dependence regarding concentration.

Determining the characteristics of sodium benzoate (E211) production by using double-linear extrapolation provides fast results for chemical kinetics.

Sodium benzoate $\left(\mathrm{NaC}_{6} \mathrm{H}_{5} \mathrm{CO}_{2}\right)$ is a preservative. It is produced by the neutralization of benzoic acid $\left(\mathrm{C}_{7} \mathrm{H}_{6} \mathrm{O}_{2}\right)$ with sodium hydroxide $(\mathrm{NaOH})$ in a stirred batch reactor under different room temperatures:

$\mathrm{NaOH}+\mathrm{C}_{7} \mathrm{H}_{6} \mathrm{O}_{2} \leftrightarrow \mathrm{NaC}_{6} \mathrm{H}_{5} \mathrm{CO}_{2}+\mathrm{H}_{2} \mathrm{O}$

The kinetic parameters and characteristics of sodium benzoate production (activation energy, reaction rate constant, rate order) were determined.
\end{abstract}

Keywords: Sodium benzoate synthesis, strong electrolyte, strong electrolyte, linear extrapolation, conductivity.

\section{INTRODUCTION}

Changes in concentration, depending on time, are basic for chemical kinetics. Eldridge and Piret [1] obtained the pseudo-first-order reaction rate constant using a batch reactor. In order to determine the acetic anhydride concentration, samples from the reactor were withdrawn into tarred flasks containing 15-20 times the quantity of saturated aniline-water required to react with the sample. Since the anhydride rapidly acetylates the aniline, thus producing acetanilide and acetic acid, the samples were then titrated to determine the concentration of acetic acid. In another study, Shatyski and Hanesian [2] determined the kinetics of the above reaction by using temperature-time data obtained under adiabatic conditions in a batch reactor. The use of in-situ FTIR spectroscopy for following the hydrolysis of acetic anhydride reaction has already been demonstrated [3]. The analysis of the batch reactor data showed that the hydrolysis of acetic anhydride is a pseudo-first order reaction. The rate constants were calculated from the batch data using both integral and differential methods of analyses.

Sodium benzoate is produced by the neutralization of benzoic acid with sodium hydroxide. It is

*Address corresponding to this author at the Faculty of Chemistry and Chemical Engineering, University of Maribor, Smetanova 17, Maribor, Slovenia; Tel: +386 02 2294454; Fax: +386 022527774

E-mail: anita.kovac@uni-mb.si bacteriostatic and fungistatic under acidic conditions. Sodium benzoate is declared on a product label as E211. Benzoic acid is a more effective preservative; whilst sodium benzoate is more commonly used as a food additive because benzoic acid does not dissolve well in water. The International Programme on Chemical Safety found no adverse effects in humans at doses of $647-825 \mathrm{mg} / \mathrm{kg}$ of body weight per day [4].

The knowledge of the chemical reaction kinetic in complex chemical systems is essential for the accurate and reliable design of reactors. It has a significant impact on the equipment needed in chemical production plants [5-9].

The problem of an accurate design of chemical reactors is not only economical, it is directly related to safety issues and hazard assessment. Simplified or inaccurate design of a chemical reactor can lead to disastrous consequences. Without knowledge of chemical kinetic the chemical process can accelerate significantly and it can lead to runaway reaction and possible explosion of a reactor [10-12].

The main problem in the modelling of complex kinetics is the huge amount of data needed to describe accurately the chemical processes. These data are not always available, and, even if they are known and accurate, in order to find important physical characteristics of a system extensive computational 
resources are required to perform numerical integration of a system of equations [13-15].

This paper studies the determination of chemical kinetics regarding the production of sodium benzoate from benzoic acid $\left(\mathrm{C}_{7} \mathrm{H}_{6} \mathrm{O}_{2}\right)$ and sodium hydroxide $(\mathrm{NaOH})$, by using the double-linear extrapolation method.

\section{THE DOUBLE-LINEAR EXTRAPOLATION METHOD}

The double-linear extrapolation method is an alternative method for determining concentration by measuring the conductivity of a strong electrolyte. This double-linear extrapolation method is a very simple method over two stages, each stage of the method looks for different constants from the sloped-lines in each diagram (Figure 1):

\subsection{First Step - Determining the Conductivity Constant}

The basis of the first step is a diagram which represents the linear time dependence regarding the difference in conductivity. The conductivity constant, $\boldsymbol{s}_{\mathrm{k}}$, can be read from the sloped-line, which is constant for each reaction. So, with a known value for the conductivity constant $S_{\mathrm{K}}$, any difference in conductivity $(\Delta \kappa)$ at a specific time $(t)$ can be determined:

$\Delta \kappa=t \cdot s_{\mathrm{K}}$

$\Delta \kappa=\kappa_{0}-\kappa_{t}$

The conductivity constant $\left(s_{\mathrm{k}}\right)$ can be determined graphically by using linear extrapolation as a slopedline (eq. 2.1). The difference in conductivity $(\Delta \kappa$; eq. 2.2) can be determined by subtracting the initial conductivity $\left(\kappa_{0}\right)$ of the conductivity, at different times $\left(\kappa_{t}\right)$.

\subsection{Second Step - Determining the Concentration Constant}

The basis of the second step is a diagram which represents the linear difference in conductivity, depending on the concentration. The concentration constant $s_{c}$, can be read from the sloped-line, which is constant for each reaction. So, with a known value for

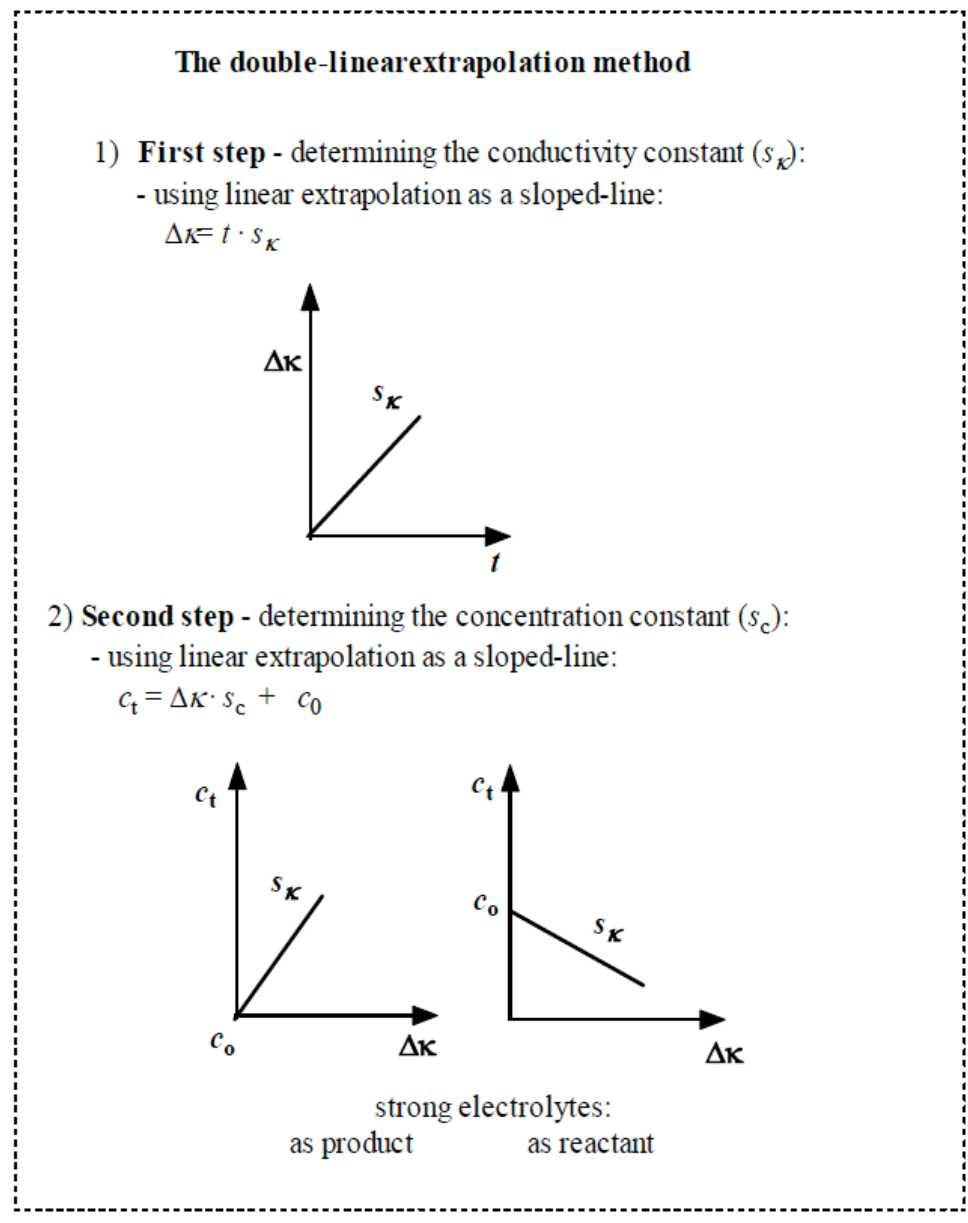

Figure 1: The double-linear extrapolation method. 
concentration constant $s_{c}$, concentration $(c)$ at a specific difference in conductivity $(\Delta \kappa)$ can be determined:

$c_{t}=\Delta \kappa \cdot s_{\mathrm{c}}+c_{0}$

Concentration constant $\left(s_{c}\right)$ can be determined graphically by using linear extrapolation as a slopedline (eq. 2.3). $c_{0}$ is the known initial concentration.

Concentration constant $\left(s_{c}\right)$ can be calculated by using equation 2.4 from a known concentration, depending on time and conductivity. This is sufficient for some data.

$s_{\mathrm{c}}=-\left(c_{0}-c_{t}\right) /\left(\kappa_{0}-\kappa_{t}\right)$

Concentration can be determined by various methods: by titration for strong electrolytes (as shown in Chapter 3) etc. The theories of strong electrolytes and double-linear extrapolation methods would produce similar values for concentration, since they are based on similar mathematical connections - both are linear dependent.

Each reaction has specifically characteristic doublelinear constants, which can be determined by using double mathematical linear extrapolation. Conductivity for a specific reaction has a specific characterization, therefore, certain linear constants can be determined, which are constant during a specific reaction. Once we know both the conductivity and concentration constants, which can be calculated after only a few known parameters (eq. 2.1 and 2.4) and can further calculate the desired concentration (eq. 2.3).

The accuracy of this method was tested by using the theory of strong electrolytes (ch. 3)

\section{DETERMINING THE CONCENTRATION BY USING THE THEORY OF STRONG ELECTROLYTES}

Strong electrolytes are substances that are almost fully ionized in solution, and include ionic solids and strong acids. As a result of their complete ionization, the concentration of ions within a solution is proportional to the concentration of the added strong electrolyte [5].

In an extensive series of measurements during the nineteenth century, Friedrich Kohlrausch showed that, at low concentrations, the molar conductivities of strong electrolytes vary linearly with the square root of the concentration:

$$
\Lambda_{\mathrm{m}}=\Lambda_{\mathrm{m}}^{\circ}-\mathrm{K} \sqrt{c}
$$

where $\Lambda_{\mathrm{m}}$ introduces the molar conductivity in siemens metre-squared per mole $\left(\mathrm{S} \mathrm{m}^{2} \mathrm{~mol}^{-1}\right)$, which is defined as:
$\Lambda_{\mathrm{m}}=\frac{\kappa}{c}$

where $c$ is the molar concentration of the added electrolyte, and $\kappa$ is the conductivity in siemens per meter $\left(\mathrm{S} \mathrm{m}^{-1}\right)$.

Equation 3.1 is called Kohlrausch's Law. The constant $\Lambda_{\mathrm{m}}^{\circ}$ is the limiting molar conductivity, the molar conductivity within the limit of zero concentration. The $\Lambda_{\mathrm{m}}^{\circ}$ for sodium hydroxide at a temperature of around $25^{\circ} \mathrm{C}$ is [5]:

$\Lambda_{\mathrm{m}}^{\circ}=5.01+19.91=24.92 \mathrm{mS} \mathrm{m}^{2} \mathrm{~mol}^{-1}=2492 \mathrm{mS} \mathrm{dm}^{2}$ $\mathrm{mol}^{-1}$

Kohlrausch's constant can be calculated by known values for initial concentration $\left(c_{0}\right)$ and initial conductivity $\left(\kappa_{0}\right)$, using equation 3.1 and 3.2 :

$\mathrm{K}=\frac{\Lambda_{\mathrm{m}}^{\circ}}{c_{0}^{0.5}}-\frac{\kappa_{0}}{c_{0}^{1.5}}$

The essence of the strong electrolytes theory is that you can determine the concentration of the reactant or product. The reaction was observed by the concentration calculation. The two basic equations 3.1 and 3.2 were used:

$\Lambda_{\mathrm{m}}^{\circ}-\mathrm{K} \sqrt{c}=\frac{\kappa}{c}$

The concentration can be expressed as a cubic equation:

$c^{3}-\frac{\Lambda_{\mathrm{m}}^{\circ} c^{2}}{\mathrm{~K}^{2}}+\frac{\Lambda_{\mathrm{m}}^{\circ} 2 \kappa c}{\mathrm{~K}^{2}}-\frac{\kappa^{2}}{\mathrm{~K}^{2}}=0$

or in general:

$a x^{3}+b x^{2}+c x+d=0$

The concentration was expressed for equation 3.5 using for the numerical method:

$c=\frac{\kappa+c^{1.5} \mathrm{~K}}{\Lambda_{\mathrm{m}}^{\circ}}$

The concentration was calculated by using a numerical method (for example successive substitution; addition A). The initial concentration $(z c)$ and the allowed differences between the initial and target values (EPS) are needed.

The determination of concentration change by using a numerical method is very long-term, so it is only used 
at the beginning in order to determine the conductivity and concentration constants when using the doublelinear extrapolation method (chapter 2.), which is faster and sufficiently precise.

The simplified chemical kinetics, which includes the excesses of other components, is described in Chapter 4.

\section{REACTION RATE}

For a constant-volume batch reactor [3], the rate at which reactant $A^{\prime}$ appears (sodium hydroxide $(\mathrm{NaOH})$ ), $r_{\mathrm{A}}$, is given by:

$-r_{\mathrm{A}}=\frac{d c_{\mathrm{A}}}{d t}$

where $r_{\mathrm{A}}$ can be expressed as:

$-r_{\mathrm{A}}=k \cdot c_{\mathrm{A}}^{n} \cdot c_{\mathrm{B}}^{m}$

where $k$ is the reaction rate constant, $n$ and $m$ are the reaction orders with respect to species $A$ (sodium hydroxide) and $B$ (benzoic acid $\left(\mathrm{C}_{7} \mathrm{H}_{6} \mathrm{O}_{2}\right)$ ), respectively.

The first benzoic acid is in excess, and $c_{\mathrm{B}}$ remains essentially unchanged during the course of the reaction:

$-r_{\mathrm{A}}=k^{\prime} \cdot c_{\mathrm{A}}^{n}$

where $k^{\prime}$ is a pseudo rate constant

$$
k^{\prime}=k \cdot c_{\mathrm{B}}^{m} \approx k \cdot c_{\mathrm{B} 0}
$$

The second sodium hydroxide is in excess, and $c_{\mathrm{A}}$ remains essentially unchanged during the course of the reaction:

$-r_{\mathrm{B}}=k^{\prime \prime} \cdot c_{\mathrm{B}}^{m}$

where $k^{\prime \prime}$ is a pseudo rate constant

$$
k^{\prime \prime}=k \cdot c_{\mathrm{A}}^{n} \approx k \cdot c_{\mathrm{A} 0}
$$

The reaction order and rate constant can be determined by the integral method of analysis. In this method, the rate expression is guessed and the differential equation used to model the batch system is integrated. If the assumed order is correct, the appropriate plot (determined from the integration) of concentration-time data should be linear.

For the first-order case where $-r_{\mathrm{A}}=k c_{\mathrm{A}}$, integration of equation 4.1 yields:

$k \cdot t=\ln \frac{c_{\mathrm{A} 0}}{c_{\mathrm{A}}}$ where $c_{\mathrm{A}}$ is the current sodium hydroxide concentration and $C_{A 0}$ is the initial sodium hydroxide concentration. Benzoic acid, $c_{\mathrm{B}}$, is in excess.

For the first-order case where, $c_{\mathrm{A}}$, sodium hydroxide is in excess:

$$
k \cdot t=\ln \frac{c_{\mathrm{B} 0}}{c_{\mathrm{B}}}
$$

where $c_{\mathrm{B}}$ is the benzoic acid concentration, and $c_{\mathrm{B} O}$ is the initial benzoic acid concentration.

For the second-order case where $-r_{A}=k c_{A}^{2}$, integration of equation 4.1 yields:

$\frac{1}{c_{A}}=\frac{1}{c_{A 0}}+k \cdot t$

For the second-order case where, $c_{A}$, sodium hydroxide is in excess:

$\frac{1}{c_{B}}=\frac{1}{c_{B 0}}+k \cdot t$

The specific reaction rate $k$, is a function of the reaction temperature, and is given by the Arrhenius equation:

$k=k_{0} \cdot e^{-\frac{E_{\mathrm{a}}}{R \cdot T}}$

where $k_{0}$ is the pre-exponential factor, $E_{\mathrm{a}}$ is the activation energy for the reaction, and $T$ is the absolute temperature.

This paper presents the chemical kinetic and characteristics determination of sodium benzoate, by using the double-linear extrapolation method.

\section{CASE STUDY - SODIUM BENZOATE SYNTHESIS}

Simplified chemical kinetics regarding the synthesis of E211, performed using different excesses of components - benzoic acid (chapter 5.1) and sodium hydroxide (chapter 5.2).

\subsection{Benzoic Acid is in Excess}

A schematic diagram of the laboratory apparatus is shown in Figure 2. A batch reactor with a stirrer was used in the experiment. Sodium hydroxide $(0.2850 \mathrm{~g})$ was dissolved in water $(0.1 \mathrm{~L})$ and heated in a reactor at a temperature of $18.5{ }^{\circ} \mathrm{C} .61 .45 \%$ surplus of benzoic acid ( $1.4035 \mathrm{~g}$ dissolved in $0.5 \mathrm{~L}$ of water) was added:

$$
\begin{aligned}
& \mathrm{NaOH}+\mathrm{C}_{7} \mathrm{H}_{6} \mathrm{O}_{2} \leftrightarrow \mathrm{NaC}_{6} \mathrm{H}_{5} \mathrm{CO}_{2}+\mathrm{H}_{2} \mathrm{O} \\
& \begin{array}{llll}
A & B & C & D
\end{array}
\end{aligned}
$$




\subsubsection{Determining the Concentration by Using the Theory of Strong Electrolytes}

Both substance were mixed and the conductivity $\left(\kappa_{t}\right)$ depending on time, $t$ (Table 1 ) was measured.
Firstly, the conductivity of the sodium hydroxide $\left(\kappa_{0}\right)$ was $4.098 \mathrm{mS} / \mathrm{dm}$.

The initial sodium hydroxide concentration $c_{\mathrm{A} 0}$, was $0.01187 \mathrm{~mol} / \mathrm{L}$. The molar conductivity at infinite

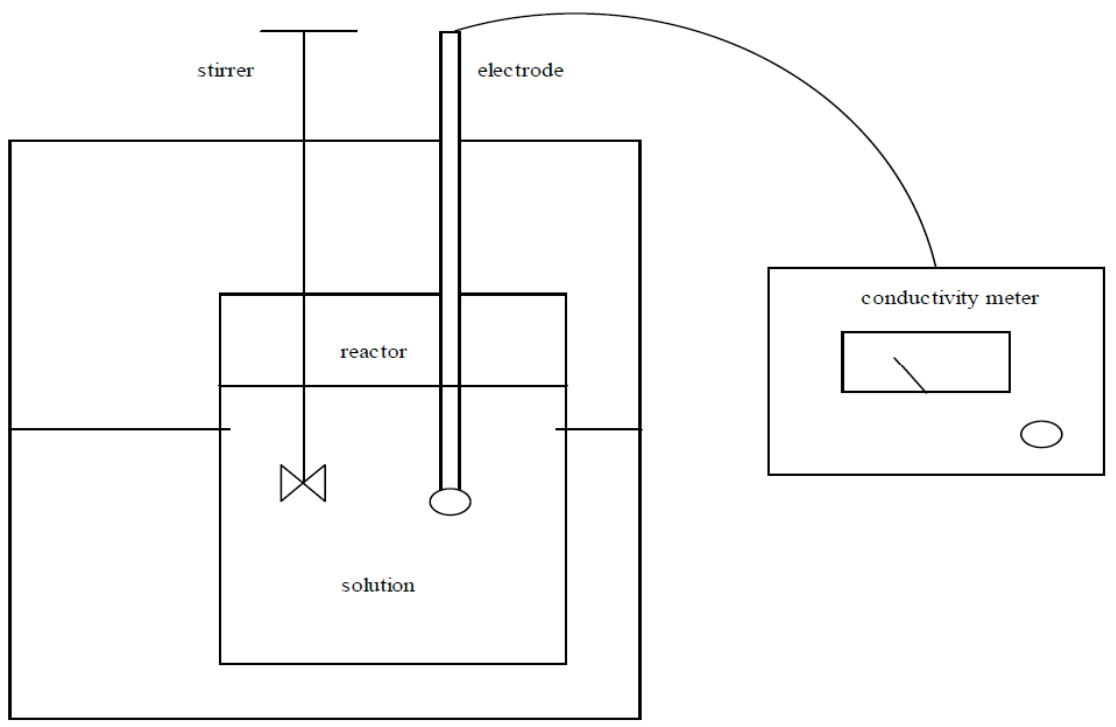

Figure 2: The apparatus - stirred batch reactor.

Table 1: The Experimental Data and Calculation at $T=18.5^{\circ} \mathrm{C}$

\begin{tabular}{|c|c|c|c|c|}
\hline$t / \mathbf{m i n}$ & $\boldsymbol{K}_{\boldsymbol{t}} /(\mathbf{m S} / \mathrm{dm})$ & $\Delta \boldsymbol{K}_{t} /(\mathrm{mS} / \mathrm{dm})$ & $\begin{array}{c}\boldsymbol{c}_{\mathrm{A}} /(\mathbf{m o l} / \mathbf{L}) \\
\text { giving by strong el. theory }\end{array}$ & $\begin{array}{c}\boldsymbol{c}_{\mathrm{A}} /(\mathbf{m o l} / \mathbf{L}) \text { giving by double } \\
\text { I. e. method }\end{array}$ \\
\hline \hline 0.00 & 4.098 & 0.000 & 0.0118700 & 0.011870 \\
\hline 0.58 & 4.084 & 0.014 & 0.0118644 & 0.011864 \\
\hline 0.70 & 4.080 & 0.018 & 0.0118628 & 0.011863 \\
\hline 0.86 & 4.077 & 0.021 & 0.0118616 & 0.011862 \\
\hline 1.06 & 4.071 & 0.027 & 0.0118592 & 0.011859 \\
\hline 1.30 & 4.065 & 0.033 & 0.0118568 & 0.011857 \\
\hline 1.50 & 4.060 & 0.038 & 0.0118548 & 0.011855 \\
\hline 1.73 & 4.056 & 0.042 & 0.0118532 & 0.011853 \\
\hline 1.88 & 4.051 & 0.047 & 0.0118512 & 0.011851 \\
\hline 2.08 & 4.047 & 0.051 & 0.0118496 & 0.011850 \\
\hline 2.23 & 4.045 & 0.053 & 0.0118488 & 0.011849 \\
\hline 2.41 & 4.041 & 0.057 & 0.0118472 & 0.011847 \\
\hline 2.56 & 4.036 & 0.062 & 0.0118452 & 0.011845 \\
\hline 2.73 & 4.034 & 0.062 & 0.0118444 & 0.011844 \\
\hline 3.00 & 4.030 & 0.064 & 0.0118428 & 0.011843 \\
\hline 3.20 & 4.027 & 0.068 & 0.0118416 & 0.011842 \\
\hline 3.58 & 4.020 & 0.071 & 0.0118388 & 0.011839 \\
\hline 4.00 & 4.010 & 0.078 & 0.0118348 & 0.011835 \\
\hline 4.65 & 4.007 & 0.088 & 0.0118336 & 0.011834 \\
\hline 5.18 & 4.000 & 0.098 & 0.0118308 & 0.011831 \\
\hline 5.86 & 3.995 & 0.103 & 0.0118288 & 0.011829 \\
\hline & & & & \\
\hline
\end{tabular}


dilution $\left(\Lambda_{\mathrm{m}}^{\circ}\right)$ of the sodium hydroxide was $2492 \mathrm{mS}$ $\mathrm{dm}^{2} \mathrm{~mol}^{-1}$ [5] at a temperature around $25^{\circ} \mathrm{C}$. Kohlrausch's constant can be calculated by known values for initial concentration $\left(c_{\mathrm{AO}}\right)$ and initial conductivity $\left(\kappa_{0}\right)$, using equation 3.4 , and was 19 $704.16 \mathrm{mS} \mathrm{dm}^{2} /\left(\left(\mathrm{mol} \mathrm{L}^{-1}\right)^{1 / 2} \mathrm{~mol}\right)$. Further concentration was calculated by using the numerical method (eq. 3.8, Table 2). The concentration depending on time $\left(c_{t}=c_{\mathrm{A}}\right)$ was calculated by using equation 3.8 (Table 1 ).

Table 2: Concentration Data were Giving by the Numerical Method

\begin{tabular}{|c|c|}
\hline$t / \min$ & $c_{\mathrm{A}} /(\mathrm{mol} / \mathbf{L})$ \\
\hline \hline 0.70 & 0.0118627 \\
\hline 0.86 & 0.0118615 \\
\hline 1.30 & 0.0118567 \\
\hline
\end{tabular}

Figure 3 illustrates the plotted sodium hydroxide concentration $c_{A}$, as a function of time at a temperature of $18.5^{\circ} \mathrm{C}$.

\subsubsection{First Step - Determining the Conductivity Constant}

The basis of the first step is the diagram which represents the measured time $(t)$, depending on the difference in conductivity ( $\Delta \kappa$; Table 1 , eq. 5.1 , Figure 4). Therefore, conductivity is measured as a function of time.

$\Delta \kappa=\kappa_{0}-\kappa_{t}=4.098-\kappa_{t}$

The conductivity constant, $s_{\mathrm{K}}$, can be read from the sloped-line, being 0.0231 (eq. 2.1), which is constant for each reaction. So, with a known value for conductivity constant $S_{\mathrm{K}}$, any difference in conductivity $(\Delta \kappa)$ at any specific time $(t)$ can be determined:

$\Delta \kappa=t \cdot s_{\mathrm{K}}=t \cdot 0.0231$

\subsubsection{Second Step - Determining the Concentration Constant}

The basis of the second step is the diagram which represents the linear difference in conductivity, depending on the concentration (Figure 5, Table 1). The concentration constant of conductivity $\left(s_{c}\right)$ for this reaction was 0.0004 (eq. 2.4, Table 1). The same value was also obtained from the sloped-line (Figure 5):

$c_{t}=\Delta \kappa \cdot s_{\mathrm{c}}+c_{0}=c_{t}=\Delta \kappa \cdot 0.0004+0.0119$

Once both the conductivity and concentration constants are known, which can be calculated after only a few known parameters (eq. 5.1 - 5.3), the desired concentration can be further calculated (Table 1).

The slope is negative, because the reactant concentration $(\mathrm{NaOH})$ is decreasing. The parameters are graphically defined, producing the ideal line. $c_{0}$ as the known initial concentration is 0.01187 .

The theories of the strong electrolytes and doublelinear extrapolation methods would give similar values for concentration, since they are both based on similar mathematical connections - both are linear dependent.

\subsubsection{Determination of Chemical Kinetics}

The basis of chemical kinetics, equation 4.1 , is incorporated within the first order (eq. 4.7). The plot of $\ln \left(C_{\mathrm{A} 0} / c_{\mathrm{A}}\right)$ as a function of time is quite linear (Figure 6). The slope of the curve represents the rate constant, $k$

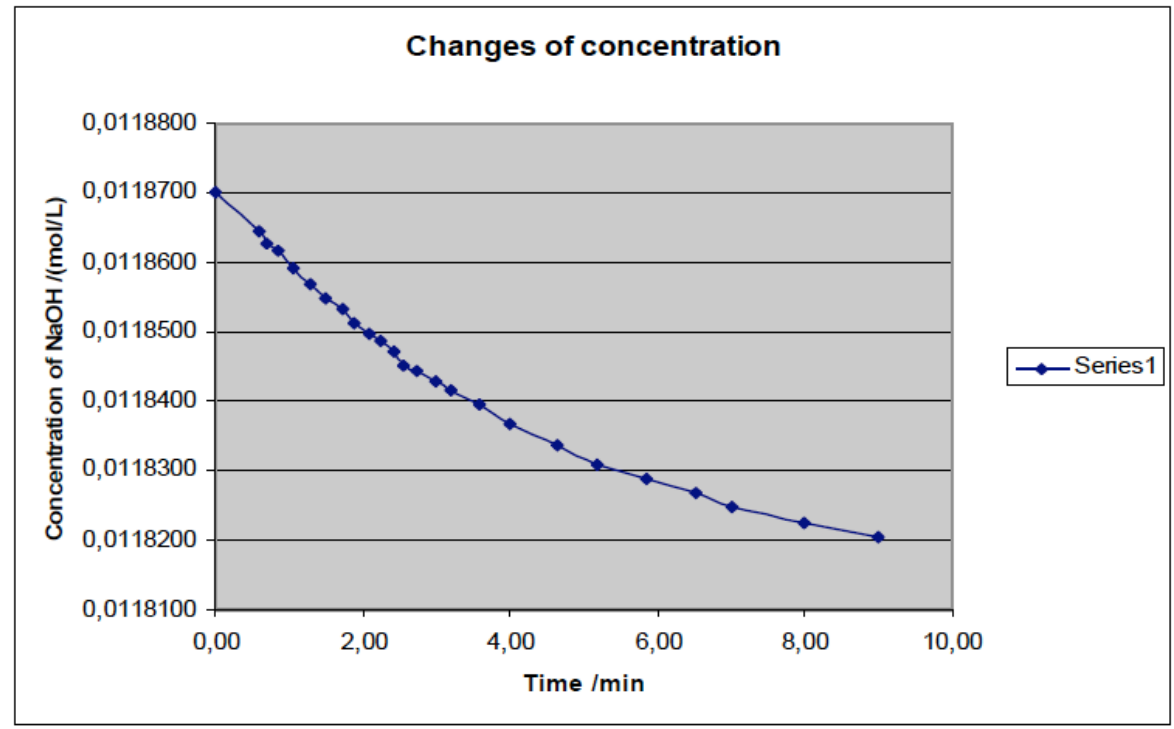

Figure 3: Concentration of sodium hydroxide $c_{\mathrm{A}}$, as a function of time at $18.5^{\circ} \mathrm{C}$. 


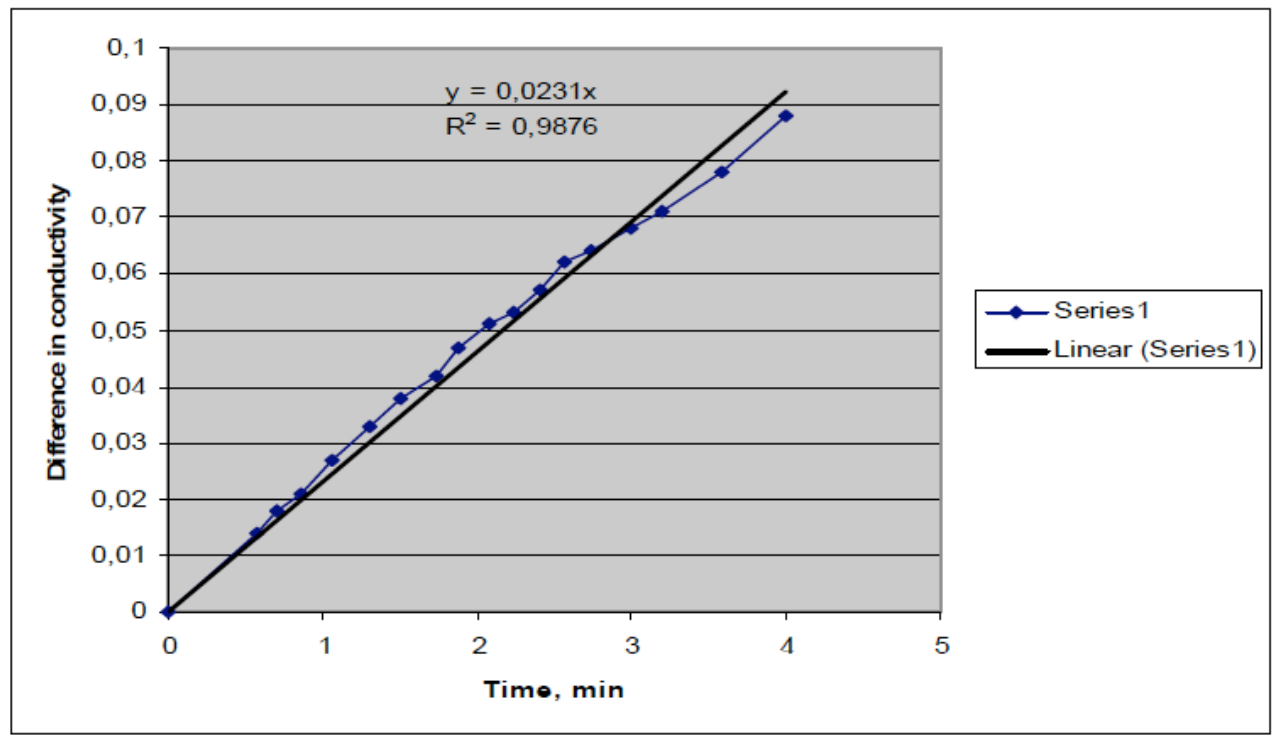

Figure 4: Difference in conductivity as a function of time.

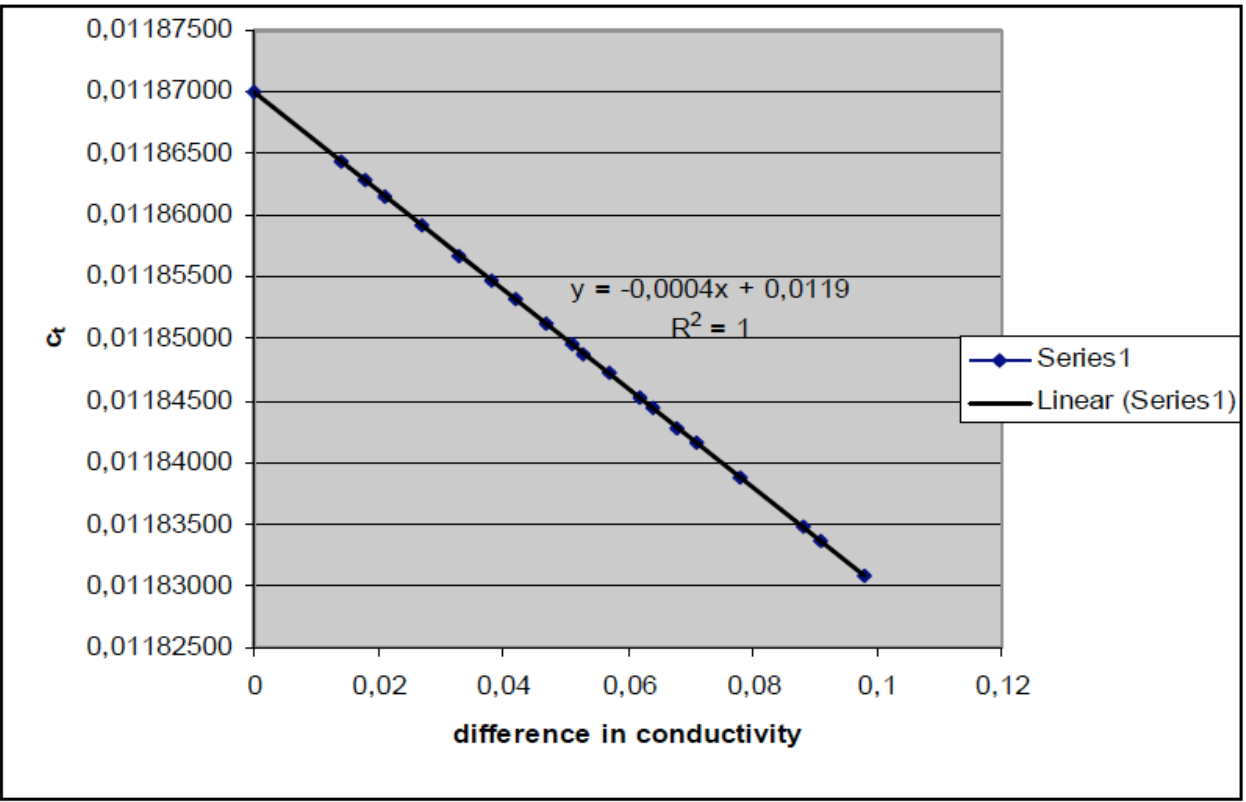

Figure 5: Concentration as a function of difference in conductivity.

(eq. 4.7). The rate constant was found to be 0.0008 $\min ^{-1}$ at $18.5^{\circ} \mathrm{C}$.

As Figure 7 illustrates, the plot of $\left(1 / c_{A}\right)$ as a function of time is linear, which suggests that the rate law is second order with respect to sodium hydroxide concentration, under given reactive conditions for excess benzoic acid. The sloped-line represents the rate constant $k$. The rate constant was found to be $0.0671 \mathrm{~L} /\left(\mathrm{mol} \mathrm{min}^{-1}\right)$ at $18.5{ }^{\circ} \mathrm{C}$ (eq. 4.9). The data shows the reaction was second order under all the temperatures studied (Table $\mathbf{3}$ ).

The experiment at temperatures $16.7 \stackrel{\circ}{ } \mathrm{C}$ and 17.2 ${ }^{\circ} \mathrm{C}$ was repeated using the same procedure.

\subsection{Sodium Hydroxide is in Excess}

\subsubsection{Determining the Concentration by Using the Theory of Strong Electrolytes}

The same experimental procedure took place for an excess concentration of sodium hydroxide. Benzoic acid (1.4046) was dissolved in water $(0.5 \mathrm{~L})$ and heated in a reactor at a temperature of $18.5{ }^{\circ} \mathrm{C}$. $52.74 \%$ surplus of sodium hydroxide was added $(0.7034 \mathrm{~g}$ dissolved in $0.1 \mathrm{~L}$ of water).

Both substances were mixed and the conductivity $\left(\kappa_{t}\right)$ measured, depending on time, $t$ (Table 4). Firstly, the conductivity of the sodium hydroxide $\left(\kappa_{0}\right)$ was $31.161 \mathrm{mS} / \mathrm{dm}$. The initial sodium hydroxide 


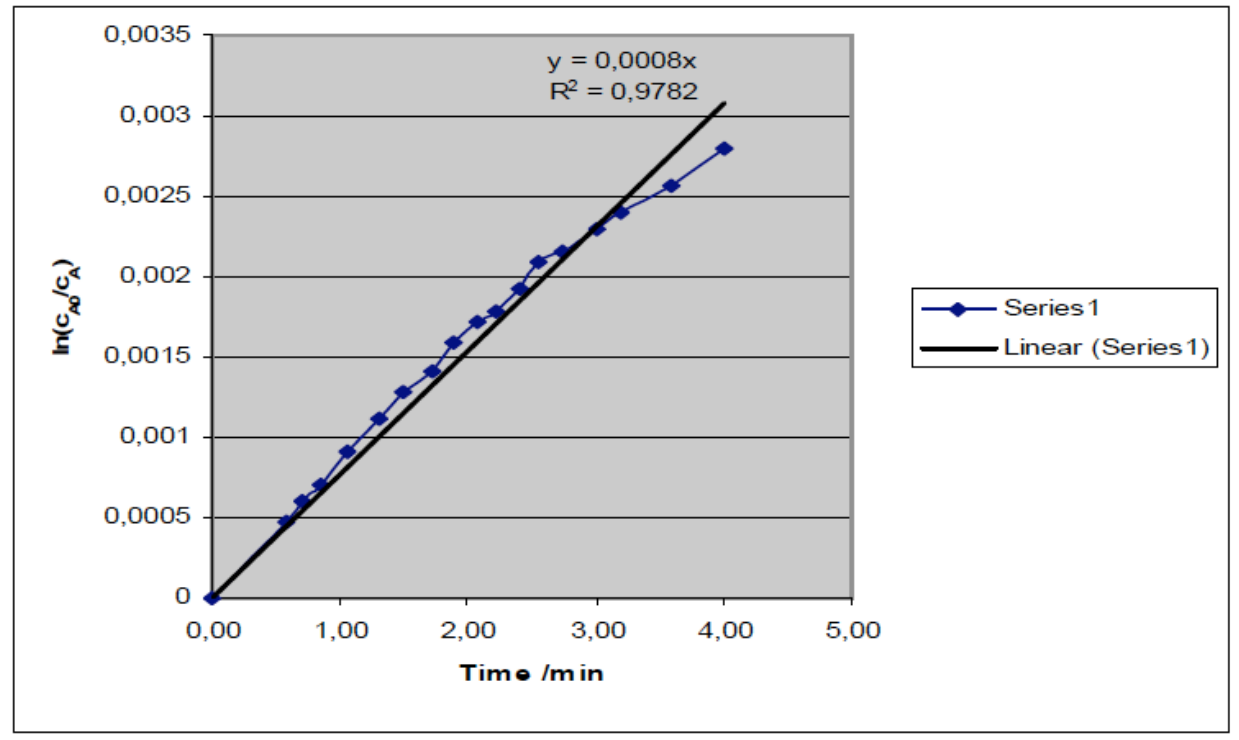

Figure 6: The plot of $\ln \left(c_{\mathrm{A} 0} / c_{\mathrm{A}}\right)$ as a function of time at $18.5^{\circ} \mathrm{C}$.

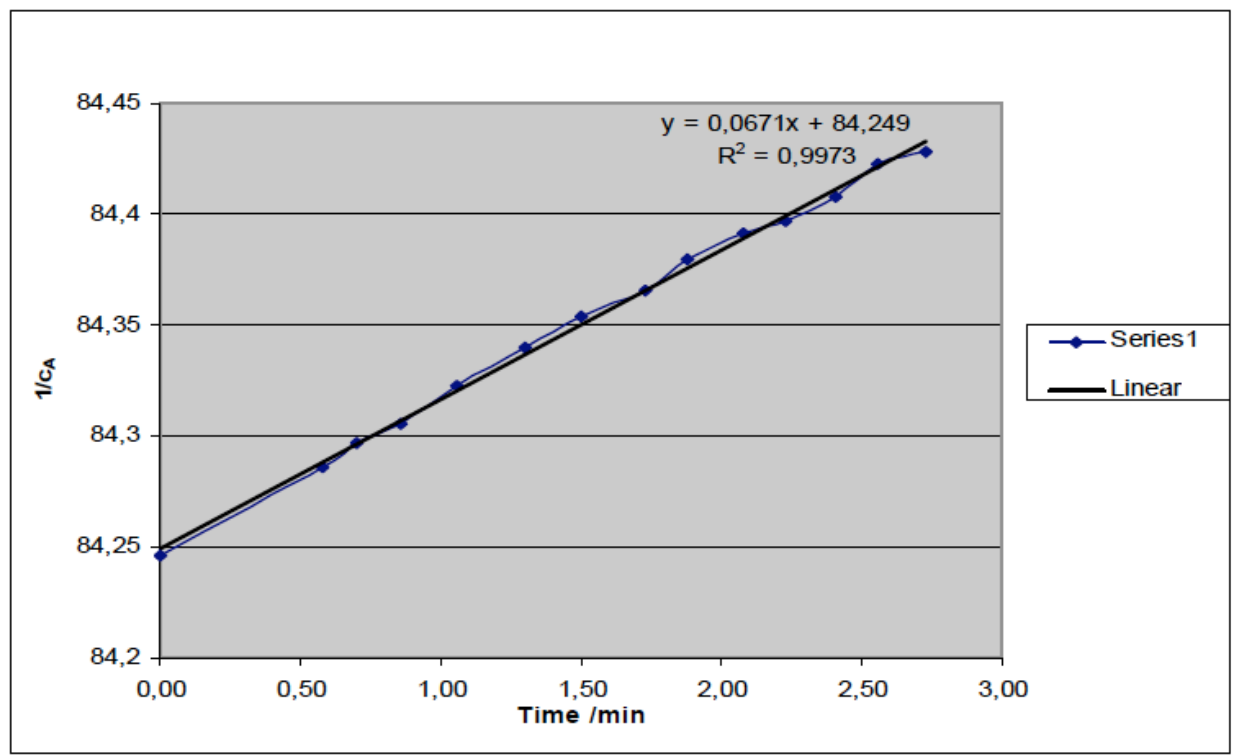

Figure 7: The plot of $\left(1 / c_{A}\right)$ as a function of time at $18.5^{\circ} \mathrm{C}$.

Table 3: The Reaction Rate Constant, $k$

\begin{tabular}{|c|c|c|c|c|}
\hline \multirow[b]{2}{*}{$\mathbf{T} / \stackrel{\circ}{ } \mathbf{C}$} & \multicolumn{2}{|c|}{ First order } & \multicolumn{2}{|c|}{ Second order } \\
\hline & $k \min ^{-1}$ & $\mathbf{R}^{2}$ & $\mathrm{k} \mathrm{L} /\left(\mathrm{mol} \mathrm{min}^{-1}\right)$ & $\mathbf{R}^{2}$ \\
\hline 16.7 & 0.0002 & 0.9682 & 0.0224 & 0.9869 \\
\hline 17.2 & 0.0007 & 0.9829 & 0.0651 & 0.9864 \\
\hline 18.5 & 0.0008 & 0.9782 & 0.0671 & 0.9973 \\
\hline
\end{tabular}

concentration, $c_{\mathrm{A} 0}$, was $0.0293 \mathrm{~mol} / \mathrm{L}$. The initial benzoic acid, $c_{\mathrm{B} 0}$, was $0.01917 \mathrm{~mol} / \mathrm{L}$. The molar conductivity at an infinite dilution $\left(\Lambda_{\mathrm{m}}^{\circ}\right)$ of sodium hydroxide was $2492 \mathrm{mS} \mathrm{dm}^{2} \mathrm{~mol}^{-1}$ [5] at a temperature of around $25^{\circ} \mathrm{C}$. Kohlrausch's constant can be calculated by known values for initial concentration
$\left(c_{\mathrm{A} 0}\right)$ and initial conductivity $\left(\kappa_{0}\right)$, using equation 3.4 and was $8345.29 \mathrm{mS} \mathrm{dm}^{2} /\left(\left(\mathrm{mol} \mathrm{L}^{-1}\right)^{1 / 2} \mathrm{~mol}\right)$. Further concentration was calculated by using the numerical method (eq. 3.8). The concentration depending on time $\left(c_{t}=c_{\mathrm{A}}\right)$ was calculated by using equation 3.8 (Table 4). 
The reacted sodium hydroxide $c_{\text {A(reacted) }}$, can be calculated (Table 4 ) by using equation (5.4):

$c_{\mathrm{A}(\text { reacted })}=c_{A o}-c_{A}$

The non-reactive benzoic acid is:

$c_{\mathrm{B}(\text { non-reacted })}=c_{B}=c_{\mathrm{B} 0}-c_{\mathrm{A}(\text { reacted })}$

Figure 8 illustrates the plot of benzoic acid concentration $\left(C_{B}\right)$ as a function of time at a temperature of $18.5^{\circ} \mathrm{C}$.

\subsubsection{First Step - Determining the Conductivity Constant}

The basis of the first step is the diagram which represents the measured time $(t)$, depending on the difference in conductivity $(\Delta \kappa$; Table 4 , eq. 5.6, Figure
9). Therefore, conductivity is measured as a function of time.

$\Delta \kappa=\kappa_{0}-\kappa_{t}=31.161-\kappa_{t}$

Conductivity constant, $s_{\mathrm{k}}$, can be read from the sloped-line, being 0.1146 (eq. 2.1), which is constant for each reaction. So, with a known value for the conductivity constant $S_{\mathrm{K}}$, the difference in conductivity $(\Delta \kappa)$ at a specific time $(t)$ can be determined:

$\Delta \kappa=t \cdot s_{\mathrm{K}}=t \cdot 1146$

\subsubsection{Second Step - Determining the Concentration Constant}

The basis of the second step is the diagram which represents the linear difference in conductivity, depending on concentration (Figure 10, Table 1). The concentration constant of conductivity $\left(s_{c}\right)$ for this

Table 4: The Experimental Data and Calculation at $T=18.5{ }^{\circ} \mathrm{C}$.

\begin{tabular}{|c|c|c|c|c|c|}
\hline$t / \min$ & $\kappa_{t} /(\mathbf{m S} / \mathbf{m})$ & $\begin{array}{c}C_{\mathrm{A}} /(\mathrm{mol} / \mathrm{L}) \text { giving by strong } \\
\text { el. theory }\end{array}$ & $\begin{array}{l}C_{\mathrm{A}} /(\mathrm{mol} / \mathrm{L}) \text { giving by } \\
\text { double l. e. method }\end{array}$ & $C_{\mathrm{A}(\text { reacted })} /(\mathrm{mol} / \mathrm{L})$ & $C_{\mathrm{B}} /(\mathrm{mol} / \mathrm{L})$ \\
\hline 0.00 & 31.161 & 0.0293000 & 0.029300 & 0.0000000 & 0.01917000 \\
\hline 0.60 & 31.140 & 0.0292916 & 0.029292 & 0.0000084 & 0.01916160 \\
\hline 0.73 & 31.130 & 0.0292876 & 0.029288 & 0.0000124 & 0.01915760 \\
\hline 0.96 & 31.090 & 0.0292716 & 0.029272 & 0.0000284 & 0.01914160 \\
\hline 1.11 & 31.060 & 0.0292596 & 0.029260 & 0.0000404 & 0.01912960 \\
\hline 1.26 & 31.030 & 0.0292476 & 0.029260 & 0.0000524 & 0.01911760 \\
\hline 1.41 & 31.010 & 0.0292396 & 0.029248 & 0.0000604 & 0.01910960 \\
\hline 1.68 & 30.960 & 0.0292196 & 0.029240 & 0.0000804 & 0.01908960 \\
\hline 1.90 & 30.920 & 0.0292036 & 0.029220 & 0.0000964 & 0.01907360 \\
\hline 2.08 & 30.890 & 0.0291916 & 0.029204 & 0.0001084 & 0.01906160 \\
\hline 2.25 & 30.870 & 0.0291836 & 0.029192 & 0.0001164 & 0.01905360 \\
\hline 2.58 & 30.820 & 0.0291636 & 0.029184 & 0.0001364 & 0.01903360 \\
\hline 2.81 & 30.790 & 0.0291516 & 0.029164 & 0.0001484 & 0.01902160 \\
\hline 3.00 & 30.760 & 0.0291396 & 0.029152 & 0.0001604 & 0.01900960 \\
\hline 3.46 & 30.700 & 0.0291156 & 0.029140 & 0.0001844 & 0.01898560 \\
\hline 3.91 & 30.650 & 0.0290956 & 0.029116 & 0.0002044 & 0.01896560 \\
\hline 4.45 & 30.590 & 0.0290716 & 0.029096 & 0.0002284 & 0.01894160 \\
\hline 4.85 & 30.550 & 0.0290556 & 0.029072 & 0.0002444 & 0.01892560 \\
\hline 5.25 & 30.520 & 0.0290436 & 0.029056 & 0.0002564 & 0.01891360 \\
\hline 5.63 & 30.480 & 0.0290276 & 0.029044 & 0.0002724 & 0.01889760 \\
\hline 6.13 & 30.450 & 0.0290156 & 0.029028 & 0.0002844 & 0.01888560 \\
\hline 6.73 & 30.400 & 0.0289956 & 0.029016 & 0.0003044 & 0.01886560 \\
\hline 7.13 & 30.370 & 0.0289836 & 0.028996 & 0.0003164 & 0.01885360 \\
\hline 7.75 & 30.340 & 0.0289716 & 0.028984 & 0.0003284 & 0.01884160 \\
\hline 9.21 & 30.260 & 0.0289396 & 0.028972 & 0.0003604 & 0.01880960 \\
\hline 10.26 & 30.220 & 0.0289236 & 0.028940 & 0.0003764 & 0.01879360 \\
\hline 12.41 & 30.130 & 0.0288876 & 0.028924 & 0.0004124 & 0.01875760 \\
\hline
\end{tabular}




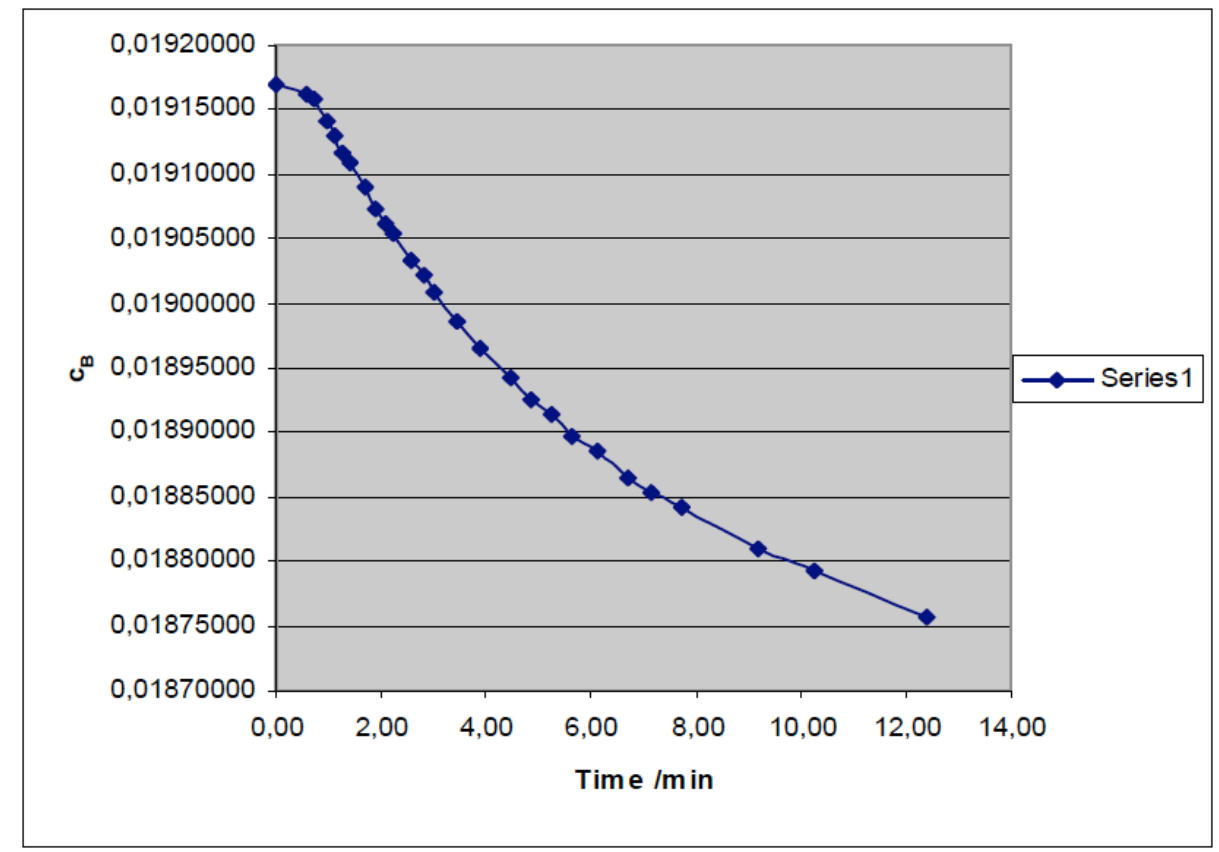

Figure 8: Concentration of benzoic acid, $c_{B}$, as a function of time at $18.5^{\circ} \mathrm{C}$.

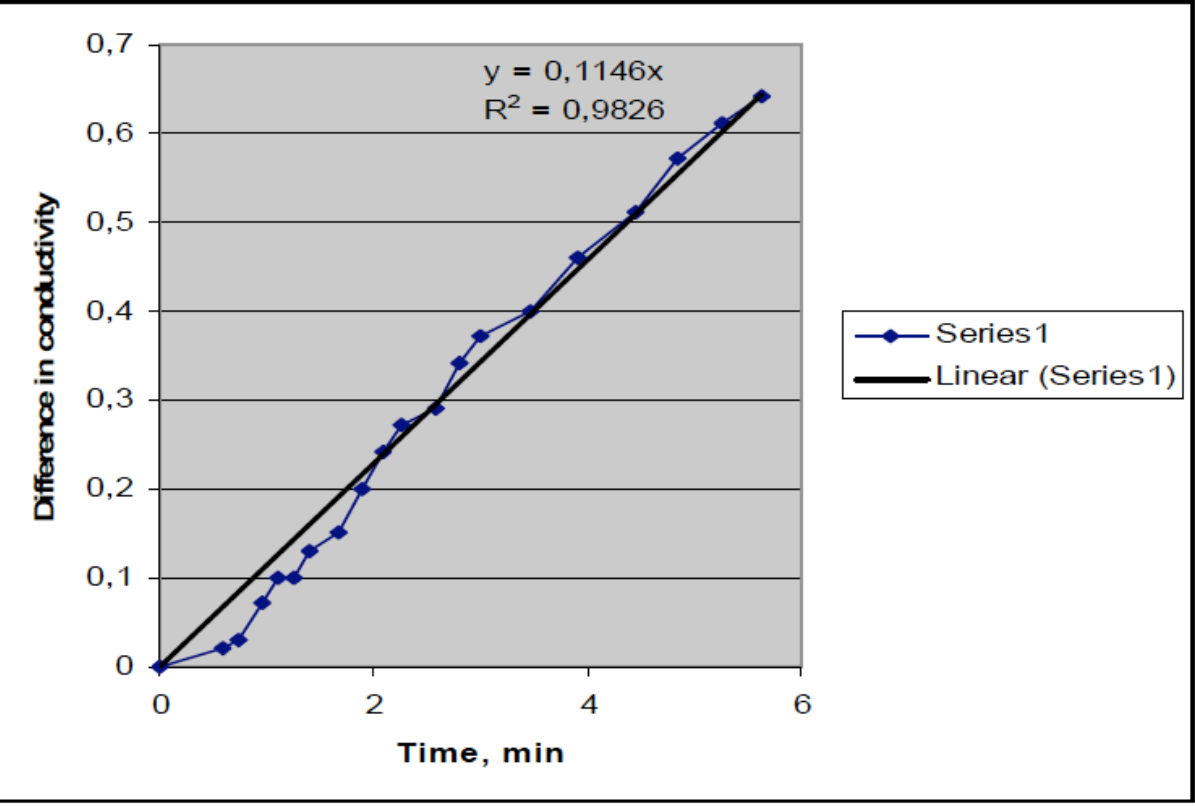

Figure 9: Difference in conductivity as a function of time.

reaction was 0.0004 (eq. 2.4, Table 4). The same value was also obtained from the sloped-line (Figure 11):

$c_{t}=\Delta \kappa \cdot s_{\mathrm{c}}+C_{0}=c_{t}=\Delta \kappa \cdot 0.0004+0.0293$

Once both the conductivity and concentration constants are known, which can be calculated after only a few known parameters (eq. 5.06 - 5.8) the desired concentration can be further calculated (Table 4).

The slope is negative, because the reactant concentration $(\mathrm{NaOH})$ is decreasing. The parameters are graphically defined, producing the ideal line. $c_{0}$, as the known initial concentration, is 0.0293 .

The values for constant concentration are the same (0.0004), regardless of the excess component.

\subsubsection{Determination of Chemical Kinetics}

The basis of chemical kinetics, equation 4.1 , is incorporated within the first order (eq. 4.7). The plot of $\ln \left(C_{\mathrm{B} O} / C_{\mathrm{B}}\right)$ as a function of time is quite linear (Figure 11; eq. 4.8). As Figure 12 illustrates, the plot of $\left(1 / C_{B}\right)$ as a function of time is linear, which suggests that the rate 


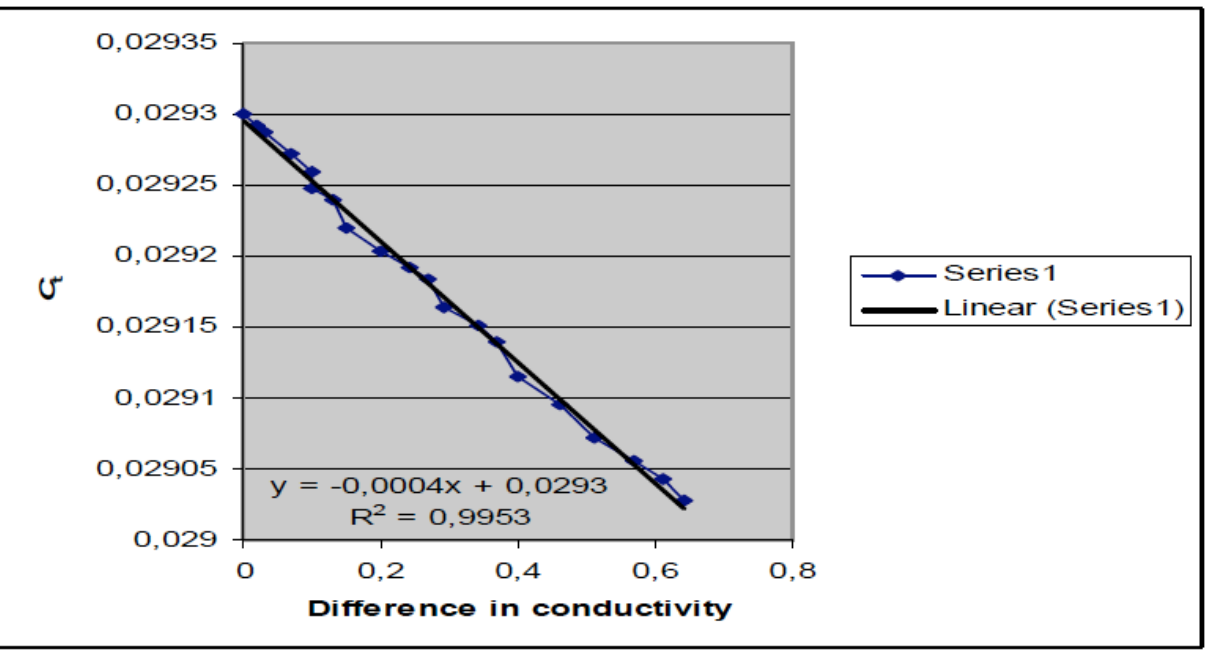

Figure 10: Concentration as a function of difference in conductivity.

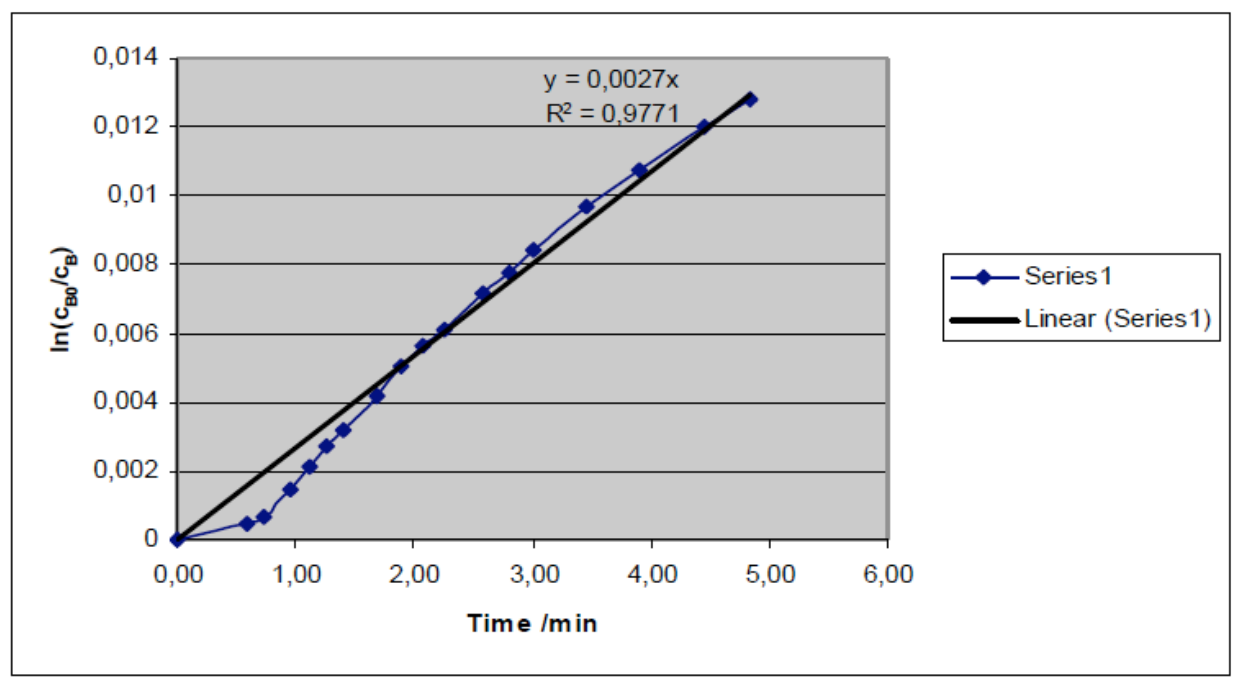

Figure 11: The plot of $\ln \left(C_{B} / C_{B}\right)$ as a function of time at $18.5^{\circ} \mathrm{C}$.

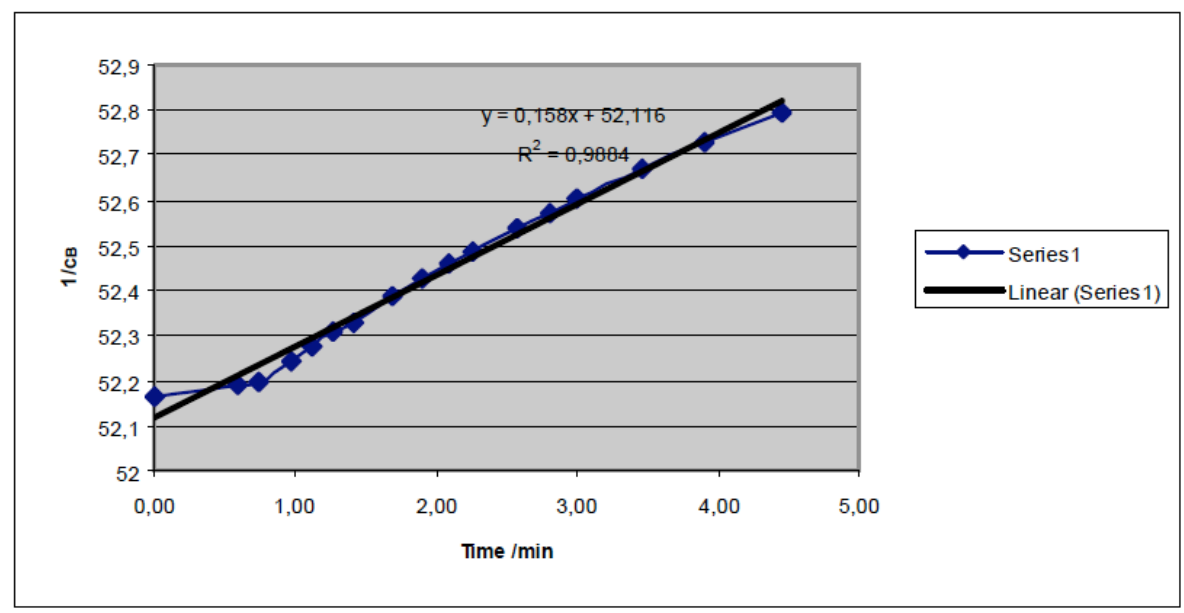

Figure 12: The plot of $\left(1 / C_{B}\right)$ as a function of time at $18.5^{\circ} \mathrm{C}$.

law is second order with respect to benzoic acid concentration, under given reactive conditions, for excess sodium hydroxide. The slope represents the rate constant $k$ (eq. 4.10). The rate constant was found to be $0.158 \mathrm{~L} /\left(\mathrm{mol} \mathrm{min}^{-1}\right)$ at $18.5^{\circ} \mathrm{C}$. The data shows the reaction is second order under all temperatures studied (Table 5). 
Table 5: The Reaction Rate Constant, $k$

\begin{tabular}{|c|c|c|c|c|}
\hline & \multicolumn{2}{|c|}{ First order } & \multicolumn{2}{c|}{ Second order } \\
\hline $\mathbf{T} / \mathbf{o} \mathbf{C}$ & $\mathbf{k ~ m i n}^{-1}$ & $\mathbf{R}^{\mathbf{2}}$ & 0.0539 & $\mathbf{R}^{\mathbf{2}}$ \\
\hline \hline 16.1 & 0.0010 & 0.9867 & 0.0686 & 0.9915 \\
\hline 17.4 & 0.0012 & 0.9772 & 0.158 & 0.9841 \\
\hline 18.5 & 0.0027 & 0.9771 & 0.9884 \\
\hline
\end{tabular}

The experiment at temperatures $16.1{ }^{\circ} \mathrm{C}$ and 17.4 ${ }^{\circ} \mathrm{C}$ was repeated using the same procedure. Taking the logarithm of the Arrhenius equation (eq. 4.11) and the activation energy is $303.92 \mathrm{~kJ} / \mathrm{mol}$ (Figure 13):

$\ln k=\ln k_{0}-\frac{E_{a}}{R \cdot T}$

$E_{\mathrm{a}}=36556 \mathrm{~K} \cdot 8.314 \mathrm{~J} /(\mathrm{mol} \mathrm{K})=303.92 \mathrm{~kJ} / \mathrm{mol}$

The slope of the graph is:

$-E_{\mathrm{a}} / R=-36556 \mathrm{~K}$

\section{CONCLUSIONS}

The double-linear extrapolation method is an alternative method for determining concentration, by measuring the conductivity of a strong electrolyte. This double-linear extrapolation method is a very simple method over two stages, each stage looks at different constants (conductivity and concentration) from the sloped-lines of different diagrams (the linear time dependence regarding the difference in conductivity and the linear difference in conductivity, depending on concentration). Each reaction has specific characteristic double-linear constants, which can be determined by using double mathematical linear extrapolation. Conductivity for a specific reaction has a specific characterization, therefore, certain linear constants can be determined, being constant during the specific reaction.

The kinetics of sodium benzoate was determined by measuring the conductivity of a strong electrolyte sodium hydroxide as a reactant, in a batch reactor. Conductivity for a specific reaction has a specific characterization, therefore, the conductivity and concentration constants can be determined, being constant during the specific reaction. Once both the conductivity and concentration constants are known, which can be calculated after only a few known parameters, the desired concentration can be further calculated.

The chemical kinetics of sodium benzoate production from sodium hydroxide and benzoic acid were determined by measuring the conductivity of sodium hydroxide using double-linear extrapolation. The reaction was of second order regarding sodium hydroxide and the same order for benzoic acid. The rate constant was found to be $0.0671 \mathrm{~L} /\left(\mathrm{mol} \mathrm{min}^{-1}\right)$ at $18.5^{\circ} \mathrm{C}$ regarding sodium hydroxide. The rate constant was found to be $0.158 \mathrm{~L} /\left(\mathrm{mol} \mathrm{min}^{-1}\right)$ at $18.5{ }^{\circ} \mathrm{C}$ regarding benzoic acid. The total reaction order is the sum of both, therefore it is of the fourth order.

The order of reaction, with respect to a certain reactant, is defined as the power to which its

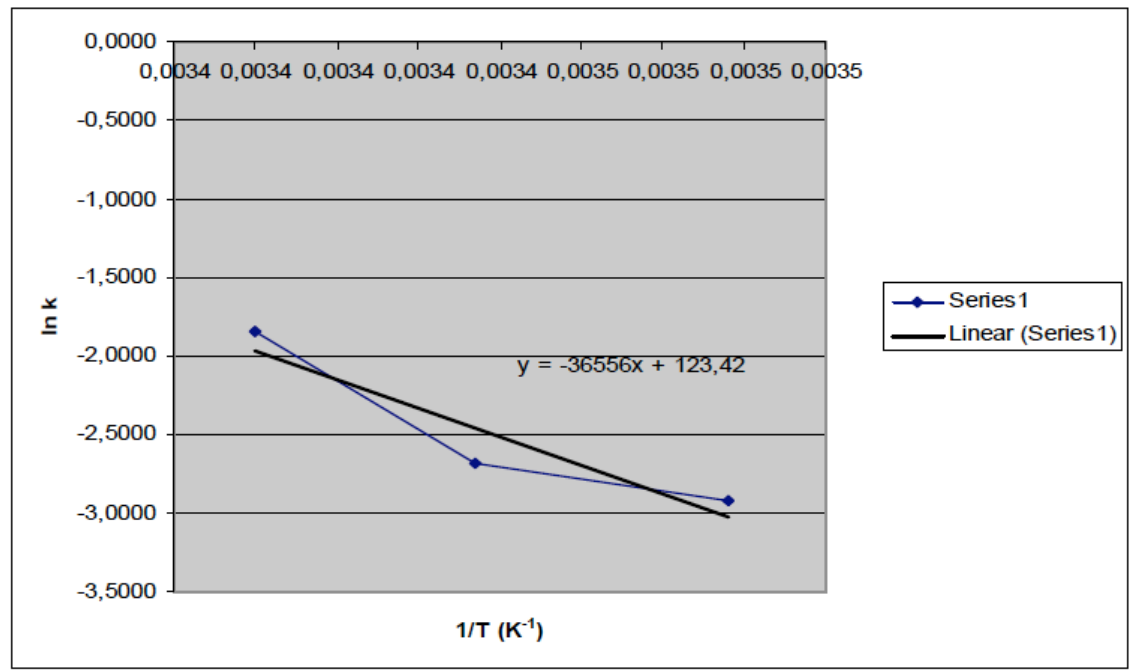

Figure 13: The plot of Ink and 1/T. 
concentration term is raised in the rate equation. Rate order presents the speed of reaction change if the concentration of the reactant is changed. If enlargement of the reaction's speed is required, the concentration with higher order must be in excess - in our case the concentrations of both reactants (sodium hydroxide and benzoic acid) were very important. The synthesis of sodium benzoate is a very fast reaction, as evidenced by the high value for activation energy. The activation energy was $303.92 \mathrm{~kJ} / \mathrm{mol}$.

Chemical kinetics plays an important role in chemical engineering, so it could represent both continuous and non-continuous methods for determining concentration. The continuous method, by using conductivity, was very useful for uninterrupted concentration measures.

\section{NOMENCLATURE}

$$
\begin{aligned}
& \text { C }=\text { concentration, } \mathrm{mol} / \mathrm{L} \\
& K=\text { constant in Kohlrausch equation, } \mathrm{mS} \\
& \mathrm{m}^{2} /\left(\left(\mathrm{mol} \mathrm{L}^{-1}\right)^{1 / 2} \mathrm{~mol}\right) \\
& k=\text { reaction rate constant } \\
& n, m=\text { rate order, } / \\
& r \quad=\text { rate of reaction } \\
& R=\text { gas law constant, } \mathrm{J} /(\mathrm{mol} \cdot \mathrm{K}) \\
& T=\text { temperature, } \mathrm{K} \\
& t=\text { time of reaction, } \min \\
& X=\text { degree of conversion, } 1 \\
& \kappa=\text { conductivity, } \mathrm{mS} / \mathrm{dm} \\
& \Lambda_{\mathrm{m}}^{\circ}=\text { molar conductivity at infinite dilution, } \mathrm{S} \mathrm{m}^{2} \\
& \mathrm{~mol}^{-1} \\
& \Lambda_{\mathrm{m}}=\text { molar conductivity, } \mathrm{S} \mathrm{m}^{2} \mathrm{~mol}^{-1}
\end{aligned}
$$

\section{ADDITION A}

$$
\begin{aligned}
& \text { Program (in FORTRAN): } \\
& z c=0.17 \\
& H=221.3 \\
& 10 c=\left(H+2458^{*} z c^{* *} 1.5\right) / 2492 \\
& \text { eps }=a b s((c-z c) / z c) \\
& z c=c
\end{aligned}
$$

if(eps.ge.0.0001) go to 10

write $\left(6,{ }^{*}\right)$ zc,c,eps

stop

end

\section{REFERENCES}

[1] Eldridge JW, Piret EL, Continuous-flow stirred-tank reactor system I. Design equations for homogeneous liquid phase reactions, Experimental data. Chem Eng Prog 1950; 46: 290.

[2] Shatyski JJ, Hanesian D. Adiabatic kinetics studies of the cytidine/acetic anhydride reaction by utilizing temperature versus time data. Ind Eng Chem Res 1993; 32: 594. http://dx.doi.org/10.1021/ie00016a004

[3] Haji S, Erkey C. Kinetics of hydrolisis of acetic anhydride by in situ FTIR spectroscopy. Chem Eng Ed 2005; 56-61.

[4] Cosmetic Ingredient Review Expert Panel Bindu Nair, Final Report on the Safety Assessment of Benzyl Alcohol, Benzoic Acid, and Sodium Benzoate. Int J Tox 2001; 20(Suppl 3): 2350.Atkins PW. Physical chemistry, Oxford, Melbourne, Tokyo: Oxford University Press, cop. 1998.

[6] Vas Bhat R, Kuipers J, Versteeg G. Mass transfer with complex chemical reaction in gas-liquid system: two-steps reversible reactions with unit stoichio-metric and kinetic orders. Chem Eng J 2000; 76: 127-52. http://dx.doi.org/10.1016/S1385-8947(99)00104-7

[7] Simmie JM. Detailed chemical kinetic models for the combustion of hydrocarbon fuels. Prog Energy Combust Sci 2003; 29: 599-34.

http://dx.doi.org/10.1016/S0360-1285(03)00060-1

[8] Elliott L, Ingham DB, Kyne AG, Mera NS, Pourkashanian M, Wilson CW. Generic algorithms for optimisation of chemicalkinetics reaction mechanisms. Prog Energy Combust Sci 2004; 30: 297-28.

\section{http://dx.doi.org/10.1016/j.pecs.2004.02.002}

[9] Heinichen H, Heyl A, Rutsch O, Weichmann J. Modeling of the coplex chemicalkinetics of the thermal decomposition of tetrachloromethane in methane. Chem Eng Sci 2001; 56: 1381-86. http://dx.doi.org/10.1016/S0009-2509(00)00361-4

[10] Smith JM, Ness HCV. Introduction to Chemical Engineering Thermodynamics, McGraw-Hill 1975.

[11] Poling BE, Prausnitz JM, O'Connell JP. The Properties of Gases and Liquids, McGraw-Hill 2000.

[12] Weinan E, Liu D, Vanden-Eijnden E. Nested stochastic simulation algorithm for chemical kinetic systems with disparate rates. J Chem Phys 2005; 123.

[13] Gibson MA, Bruck J. Efficient exact stochastic simulation of chemical systems with many species and many channels. $J$ Phys Chem 2000; 104: 1876-89.

http://dx.doi.org/10.1021/jp993732q

[14] McQuarrie DA. Stochastic approach to chemicalkinetics. J Appl Probab 1967; 4: 413-78. http://dx.doi.org/10.2307/3212214

[15] Delogu F, Monagheddu M, Mulas G, Schiffini L, Cocco G. Some kinetic features of mechanical alloying transformation processes. J Non-Cryst Solids 1998; 383-89. http://dx.doi.org/10.1016/S0022-3093(98)00550-X 